\title{
Demographic characteristics of patients with extrapulmonary tuberculosis in Germany
}

\author{
M. Forssbohm*,\#, M. Zwahlen ${ }^{\star}$, R. Loddenkemper ${ }^{\#}$ and H.L. Rieder ${ }^{+}$
}

ABSTRACT: The aim of the present study was to determine the demographics of patients with extrapulmonary tuberculosis in Germany.

Data on 26,302 tuberculosis cases from a national survey carried out during the period 19962000 were analysed.

The crude proportion of tuberculosis patients with extrapulmonary manifestations was $21.6 \%$. Extrapulmonary tuberculosis was most likely among females, children aged $<\mathbf{1 5}$ yrs and persons originating from Africa and Asia. Females tended to be more likely to have any form of extrapulmonary tuberculosis than males, except pleural tuberculosis. The strength of this association was strongest in the age range 25-64 yrs and less pronounced amongst the oldest patients. Children were particularly prone to the development of lymphatic and meningeal tuberculosis, whereas the likelihood of genitourinary tuberculosis increased with increasing age. Asian and African patients were generally more likely than persons from other areas to have lymphatic, osteoarticular, meningeal and miliary tuberculosis.

The analysis shows important differences, by age, sex and origin, in the likelihood of a tuberculosis patient presenting with extrapulmonary tuberculosis. Since the relative contribution of the foreign-born to tuberculosis in low-prevalence countries is rising, extrapulmonary tuberculosis must be taken into account more often in the differential diagnostic work-up of these patients, particularly among those originating from Asia and Africa.

\section{KEYWORDS: Age, epidemiology, extrapulmonary, Germany, sex, tuberculosis}

$$
\text { 】: }
$$
n contrast to reports from other industrialised countries [1,2], no change in the proportion of extrapulmonary tuberculosis has been reported in Germany since the 1990s [3]. In addition to the impact of infection with HIV and demographic changes in the tuberculosis population, other factors may affect the proportion of tuberculosis patients with extrapulmonary manifestations.

In Germany, little is known about HIV infection among tuberculosis patients, since such investigation is neither routinely carried out nor are the results notifiable [4,5]. Furthermore, tuberculosis continued to decline at the time the greatest increase in AIDS was noted [6]. An ongoing study by the German Central Committee against Tuberculosis (Berlin, Germany) shows that the prevalence of HIV infection continues to play a minor role among tuberculosis patients, irrespective of their provenance (German Central Committee against Tuberculosis, unpublished data).
The present study describes some key demographic and clinical characteristics of patients with extrapulmonary tuberculosis in Germany.

\section{METHODS}

During the 5-yr period 1996-2000, a total of 52,455 tuberculosis cases were notified in Germany, a country with $\sim 82$ million inhabitants. This corresponds to an average annual notification rate of 12.8 cases per 100,000 population. In order to obtain more detailed information on tuberculosis patients living in Germany, a large survey was conducted during a study period encompassing the years 1996-2000 [7]. In the 16 states that constitute Germany, 467 public health service offices, one at each district level, were asked to participate in the present study. Of these, 257 (55\%) participated continuously. A questionnaire was completed by these offices, providing information on the demographic characteristics of patients (age, sex, residence, citizenship, country of birth and time of
AFFILIATIONS

${ }^{*}$ Public Health Centre, Wiesbaden and

\#German Central Committee against Tuberculosis, Berlin, Germany. "Institute of Social and Preventive Medicine, University of Berne, Berne, Switzerland.

${ }^{+}$International Union Against Tuberculosis and Lung Disease, Paris, France.

CORRESPONDENCE

H.L. Rieder

Jetzikofenstrasse 12

3038 Kirchlindach

Switzerland

E-mail: TBRieder@tbrieder.org

Received:

February 192007

Accepted after revision:

August 282007

STATEMENT OF INTEREST

None declared.

European Respiratory Journa Print ISSN 0903-1936 Online ISSN 1399-3003 
immigration of foreigners to Germany), disease-specific characteristics (site and form of disease, bacteriological findings and drug susceptibility test results) and socioeconomic factors (source of income and housing characteristics). This information was centrally collated and computerised. The cases contributed to the study by the participating public health service offices constituted $\sim 50 \%$ of all cases reported in Germany. A comparison of patient characteristics between the study population and the total patient population suggested close comparability in all characteristics examined (age distribution, sex and proportion foreign-born).

Until the end of the year 2000, all notified tuberculosis cases in Germany had been classified as respiratory (including pulmonary, intrathoracic lymphatic and pleural) tuberculosis. In the present study, in addition to the respiratory classification system, the more detailed classification into pulmonary and extrapulmonary tuberculosis (including intrathoracic lymphatic and pleural tuberculosis) was applied according to the European consensus on surveillance of tuberculosis [8]. This allowed flexibility to reclassify tuberculosis according to the older system, yet, at the same time, comparison with others, such as the classification scheme of the US Centers for Disease Control and Prevention and the American Thoracic Society [9]. Since 2001, the new classification system alone has been in use.

Having extrapulmonary tuberculosis was the main outcome of the present analyses, and the proportion of extrapulmonary tuberculosis patients was calculated by dividing the number of patients with extrapulmonary tuberculosis by the total number of patients (in respective age or origin groups). Multivariable logistic regression models, with extrapulmonary tuberculosis as the outcome variable, were subsequently fitted. The models included indicator variables for being female and belonging to the specified age groups and regions of origin. The models included appropriately constructed effect modification terms to assess effect modifications between sex and age groups and age groups and region of origin. Models with and without effect modification terms were compared using likelihood ratio tests, and substantial effect modifications were found. Owing to the complexity of communicating results from models including several effect modification terms, it was decided to present the results of the stratified analyses as the relative odds of having extrapulmonary tuberculosis for female compared with male patients, stratified by age group and country/area of origin with $95 \%$ confidence intervals obtained from stratified logistic regression models.

\section{RESULTS}

During the study period, a total of 26,333 cases were reported in the study area. Of these, 13 were of unknown age, 15 were of unknown sex and three were of both unknown sex and age. These 31 cases were excluded from the analysis, and thus 26,302 cases were included in all analyses.

Of the 20,627 cases of pulmonary tuberculosis, $73.4 \%$ had bacteriological confirmation of Mycobacterium tuberculosis complex by culture, compared with $59.3 \%$ of the 5,675 extrapulmonary cases (table 1). Among extrapulmonary cases, bacteriological confirmation was most frequent for genitourinary tuberculosis $(77.9 \%)$ and lowest among cases with intrathoracic lymphatic tuberculosis (38.8\%).

\begin{tabular}{|c|c|c|c|c|}
\hline \multirow[t]{3}{*}{ TABLE 1} & \multicolumn{4}{|c|}{$\begin{array}{l}\text { Frequency of bacteriological culture confirmation } \\
\text { of Mycobacterium tuberculosis complex among } \\
\text { reported tuberculosis cases by site of disease, } \\
\text { Germany, 1996-2000 }\end{array}$} \\
\hline & & \multicolumn{2}{|c|}{ Culture confirmation } & \multirow[t]{2}{*}{ Total } \\
\hline & & Present & Absent & \\
\hline \multicolumn{2}{|l|}{ Total } & $18501(70.3)$ & 7801 & 26302 \\
\hline \multicolumn{2}{|c|}{ Pulmonary } & $15134(73.4)$ & 5493 & 20627 \\
\hline \multicolumn{2}{|c|}{ Extrapulmonary } & 3367 (59.3) & 2308 & 5675 \\
\hline \multicolumn{2}{|c|}{ Lymphatic, peripheral } & $859(51.0)$ & 826 & 1685 \\
\hline \multicolumn{2}{|c|}{ Lymphatic, intrathoracic } & 223 (38.8) & 352 & 575 \\
\hline \multicolumn{2}{|c|}{ Pleural } & $579(55.2)$ & 470 & 1049 \\
\hline \multicolumn{2}{|c|}{ Genitourinary } & $746(77.9)$ & 212 & 958 \\
\hline \multicolumn{2}{|c|}{ Osteoarticular } & $326(71.3)$ & 131 & 457 \\
\hline \multicolumn{2}{|c|}{ Miliary } & $126(68.5)$ & 58 & 184 \\
\hline \multicolumn{2}{|l|}{ Meningeal } & $91(68.4)$ & 42 & 133 \\
\hline \multicolumn{2}{|l|}{ Peritoneal } & $65(56.0)$ & 51 & 116 \\
\hline \multicolumn{2}{|l|}{ Cutaneous } & 70 (60.9) & 45 & 115 \\
\hline \multicolumn{2}{|l|}{ Other } & $282(70.0)$ & 121 & 403 \\
\hline
\end{tabular}

The crude prevalence of extrapulmonary tuberculosis as the major disease site was $21.6 \%$ (5,675 cases; table 2$)$. The proportion with an extrapulmonary location differed considerably by the three characteristics that were examined: females had extrapulmonary tuberculosis almost twice as frequently as males; children aged $<15$ yrs had by far the highest proportion among all age groups; and persons originating from Asia or Africa had an extrapulmonary tuberculosis prevalence of $>30 \%$.

Of all patients with extrapulmonary tuberculosis, $58.7 \%$ were born in Germany, 32.1\% were from places with a higher risk of extrapulmonary tuberculosis than Germany (i.e. other Western European countries, Turkey, Africa, Asia and other/unknown) and $9.2 \%$ from places with a lower risk (i.e. Eastern Europe and the Newly Independent States of the former Soviet Union; table 2).

Of the 9,646 foreign-born patients, information was available on month and year of entry into Germany for $53.5 \%(5,160)$. Among these, tuberculosis was diagnosed in $89.3 \%(4,607)$ within the first 12 yrs after arrival. Considering the latter 4,607 cases alone, in $44.7 \%(1,565)$ of the 3,502 with pulmonary tuberculosis, the diagnosis was made within the first year, whereas the respective proportion among the 1,105 cases with extrapulmonary tuberculosis was $28.1 \%$ (310). The annual frequency dropped sharply in subsequent years for both pulmonary and extrapulmonary tuberculosis (fig. 1), with a similar shape of decline, but more protracted for extrapulmonary than pulmonary tuberculosis.

In all countries, and in virtually every age group, females were more likely than males to have extrapulmonary tuberculosis (fig. 2). Up to the age of 24 yrs, the differences were often not significant but they tended to be significant among older patients, when the number of patients was large and the confidence intervals thus narrower. There was also a tendency 


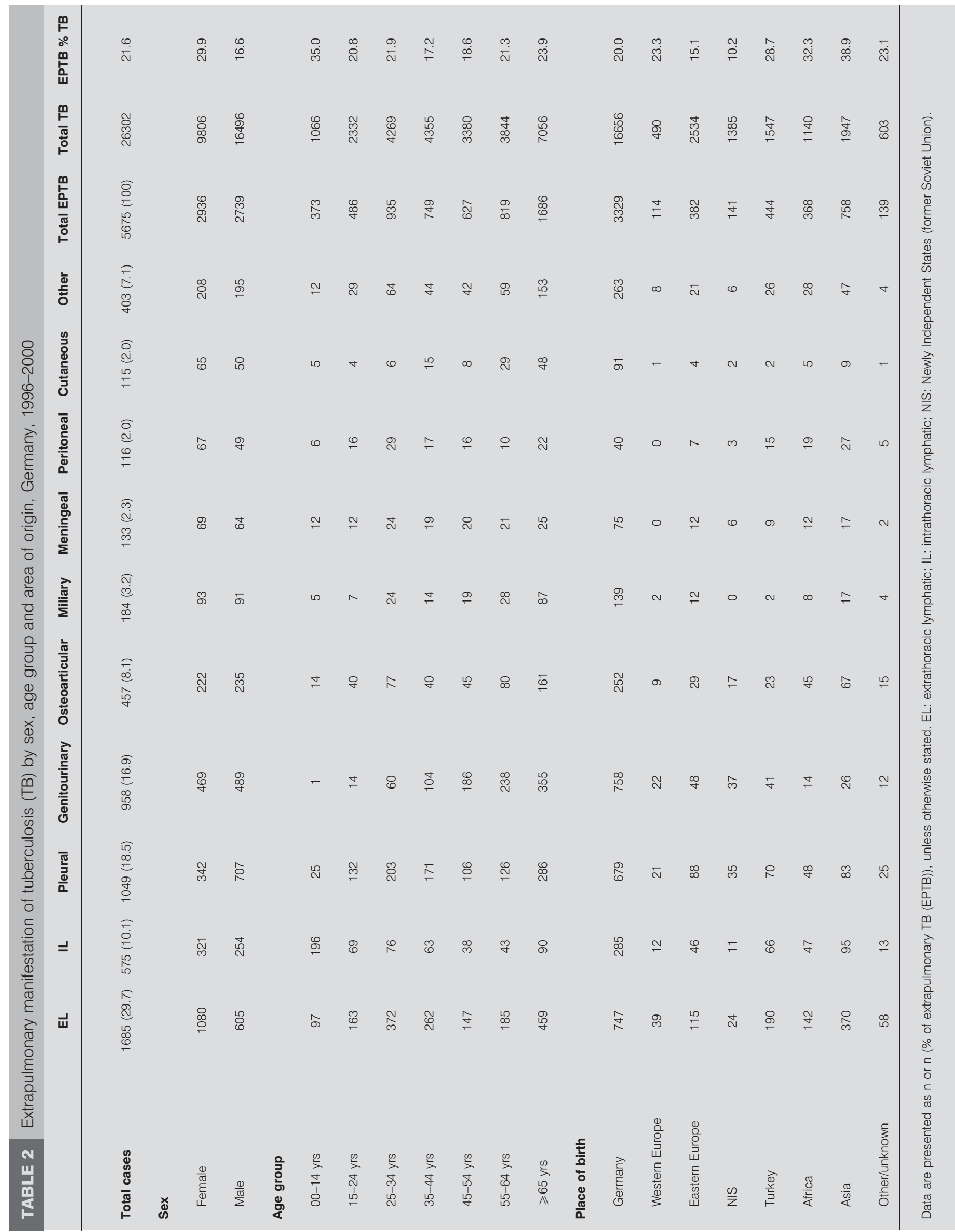




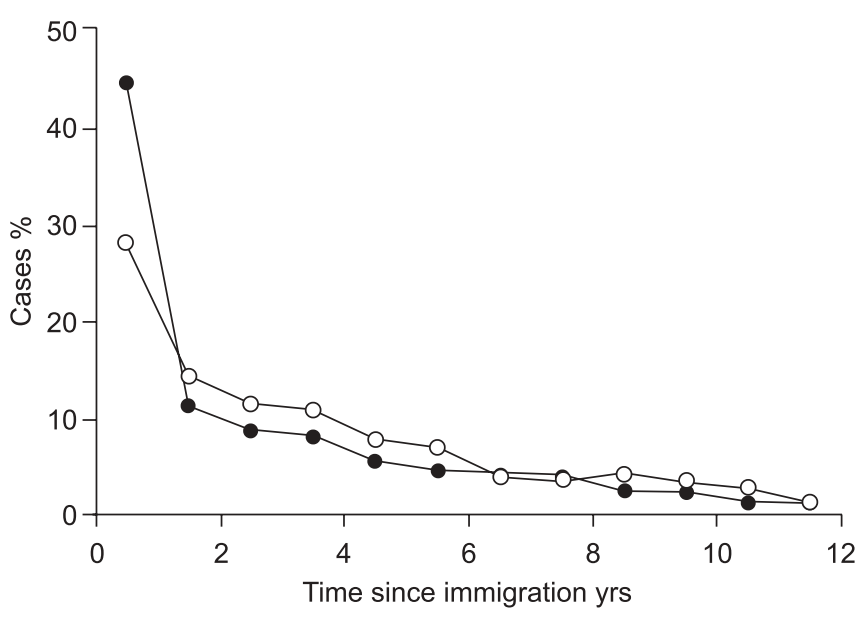

FIGURE 1. Interval between immigration into Germany and diagnosis of tuberculosis ( : pulmonary; $\bigcirc$ : extrapulmonary) among the foreign-born in Germany, 1996-2000

that the odds of being female decreased again among the oldest patients, with the notable exceptions of patients from Asia and former Western European countries other than Germany.

The eight most frequent extrapulmonary sites were stratified by age and sex, and the odds of being a female with extrapulmonary tuberculosis determined (fig. 3). Except for pleural tuberculosis (no overall increase in odds) and miliary tuberculosis, the age-specific odds appeared to be bimodal, with a nadir in the age groups in the range 15-34 yrs and a peak in those aged 45-64 yrs.

The proportion of foreign-born tuberculosis cases in Germany rose from $31.4 \%$ in 1996 to $37.4 \%$ in 2000 . However, the growth of the fraction born in Turkey, Africa and Asia during this period, from $15.5 \%$ to $18.5 \%$, was evidently too small to impact on the overall proportion of extrapulmonary tuberculosis cases, which remained stable at $21.6 \%$ on average (data not shown).

\section{DISCUSSION}

The present data were collected in a national survey inviting all health depts to participate in the study. As participation in this survey was voluntary, it was not possible to ensure representative sampling. Nevertheless, more than half of the health depts participated continuously over a period of $5 \mathrm{yrs}$, and a comparison of certain characteristics of participation with the available characteristics of all patients reported during this period in Germany lends some credibility to the idea that the participating centres catered for a clientele similar to that of the rest of the country.

Tuberculosis among immigrants tends to frequently cluster in the initial period following arrival [10, 11]. What has been shown for the UK and USA [11] was similarly apparent in the present study. This contrasts with findings from Denmark, where the risk of tuberculosis continued to emerge at a similar magnitude over a prolonged period of time subsequent to immigration [12]. Although screening of immigrants may partially explain the identification of prevalent cases at the time of entry, an important contributor to early occurrence is seemingly the role of recently acquired infection in the country of origin [10] and the declining risk of progression with time elapsed since infection [13]. In Denmark, transmission within the foreign population after arrival was estimated to account for a quarter of cases among Somali residents; however, the majority of cases were still attributed to acquisition of $M$. tuberculosis infection before immigration. The observation of a delayed presentation of extrapulmonary compared with pulmonary tuberculosis relative to time of immigration may be partially explained by screening at entry, which prominently targets pulmonary tuberculosis. Furthermore, many forms of extrapulmonary tuberculosis are manifestations emerging on average after a longer interval following acquisition of infection than pulmonary tuberculosis [14].

The emergence of tuberculosis among immigrants can be largely attributed to an infection that has been acquired in their country of origin [15]. Nevertheless, data from the Netherlands [16] and Denmark [17] clearly show that transmission of $M$. tuberculosis among immigrants also takes place following arrival, and that this may account, in certain settings, for a considerable proportion of cases [17].

Differences in the likelihood of extrapulmonary tuberculosis have been observed in various studies among tuberculosis patients by demographic characteristics. However, the reasons remain by and large elusive. On the individual level, there are indications for subtle anomalies in innate immune function [18, 19]. However, it is difficult to reconcile how such differences might apply to larger population groups and find different expression for various sites of disease.

It is established that certain forms of tuberculosis, such as intrathoracic lymphatic tuberculosis [20, 21], have a predilection for young ages [14], whereas genitourinary tuberculosis is rarely found in children [1, 2, 22]. Such differences may partially be explained by maturation factors and development of the cellular immune system [23]. Furthermore, the manifestation of tuberculosis is intrinsically linked to time elapsed since infection was acquired, making it difficult to separate the modifying effects of age and time since infection. Common wisdom holds, for instance, that pleural tuberculosis is intrinsically linked to recent acquisition of infection. However, this notion is seemingly substantiated in some [24], but not confirmed in other, studies employing molecular characterisation of strains [25].

As observed in other studies, female tuberculosis patients were, with the exception of those with pleural tuberculosis, considerably more likely to present with an extrapulmonary manifestation than male patients [1]. The reasons for this preponderance are not clearly known. The increased likelihood of females with tuberculosis presenting with an extrapulmonary disease manifestation was particularly pronounced among those aged 45-64 yrs. An explanation for this finding remains elusive, but it suggests that endocrine factors might play a role.

The differences in the proportion of extrapulmonary tuberculosis by area of origin are remarkable. Patients from Africa and Asia were generally far more likely to present with extrapulmonary tuberculosis than those from Germany. The recent demonstration that a loss-of-function polymorphism in the 

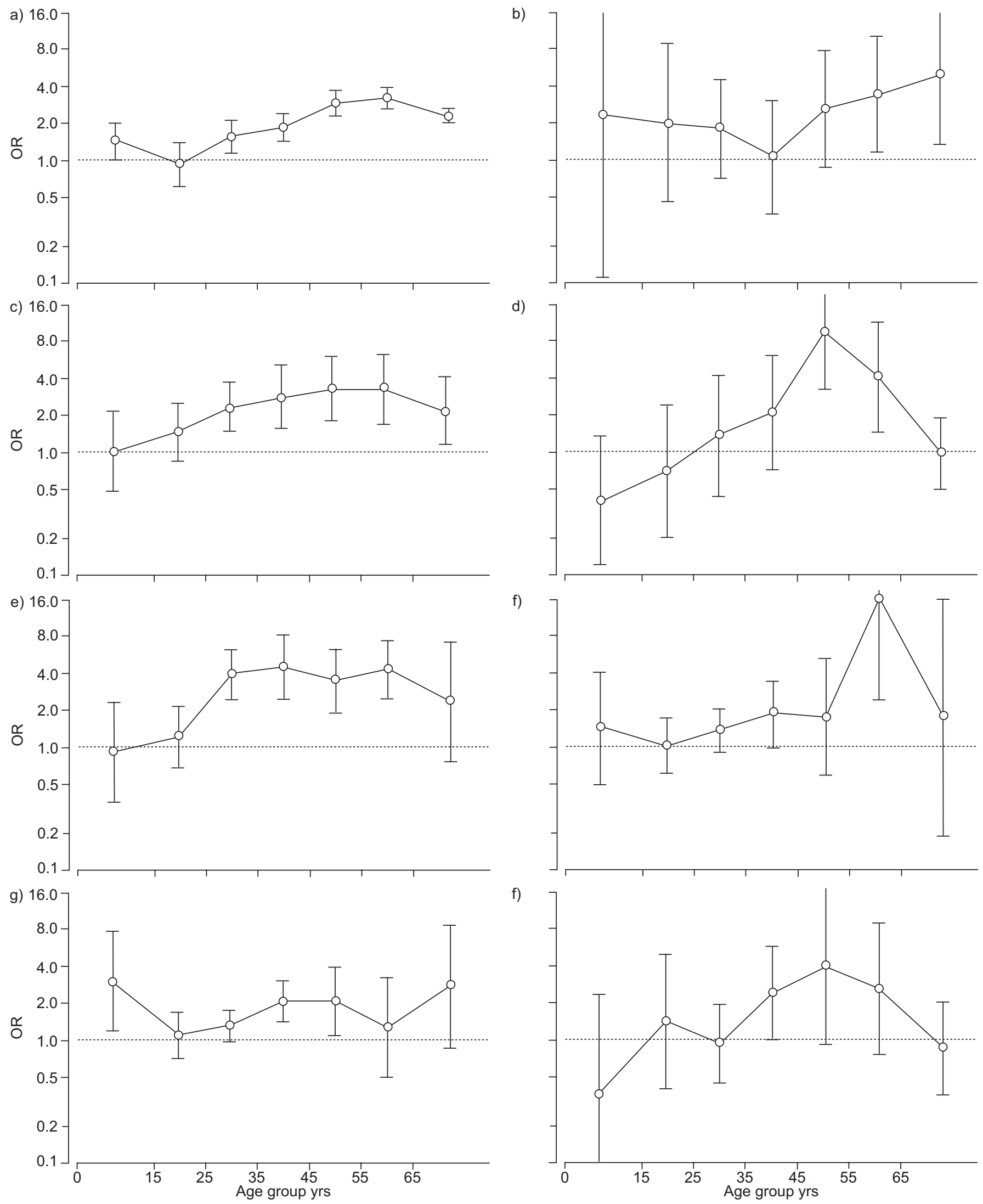

d)

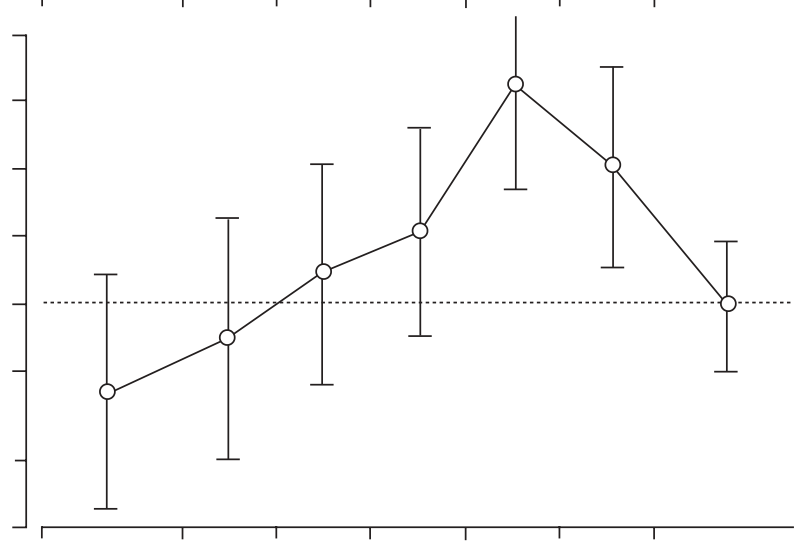

f)

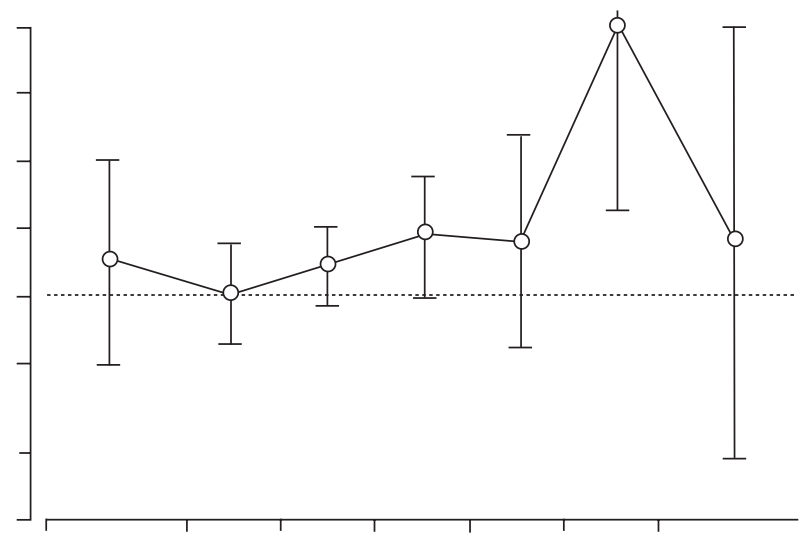

f)

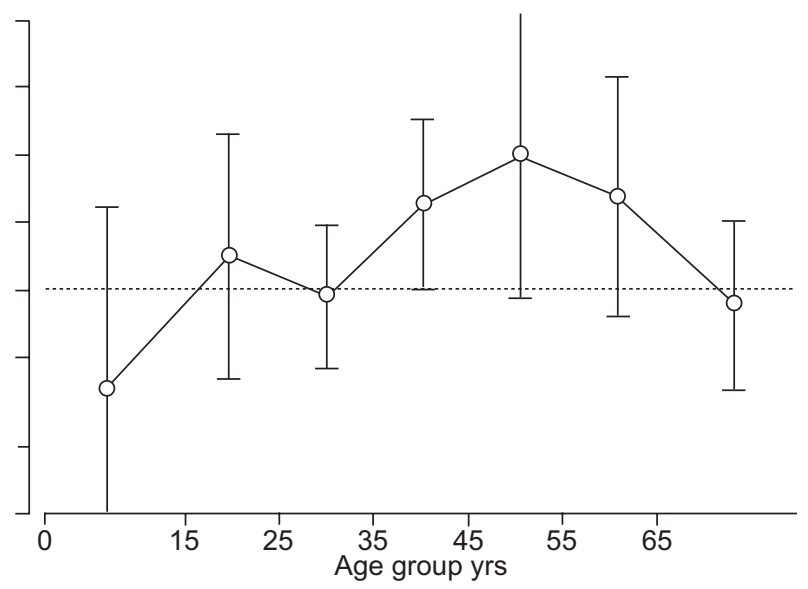

FIGURE 2. Female-to-male odds ratio (OR) of having extrapulmonary tuberculosis by age group and place of origin: a) Germany; b) former Western European countries other than Germany; c) former Eastern Europe; d) Newly Independent States (former Soviet Union); e) Turkey; f) Africa; g) Asia; and h) other areas. Vertical bars represent $95 \%$ confidence interval (…......: unity). 


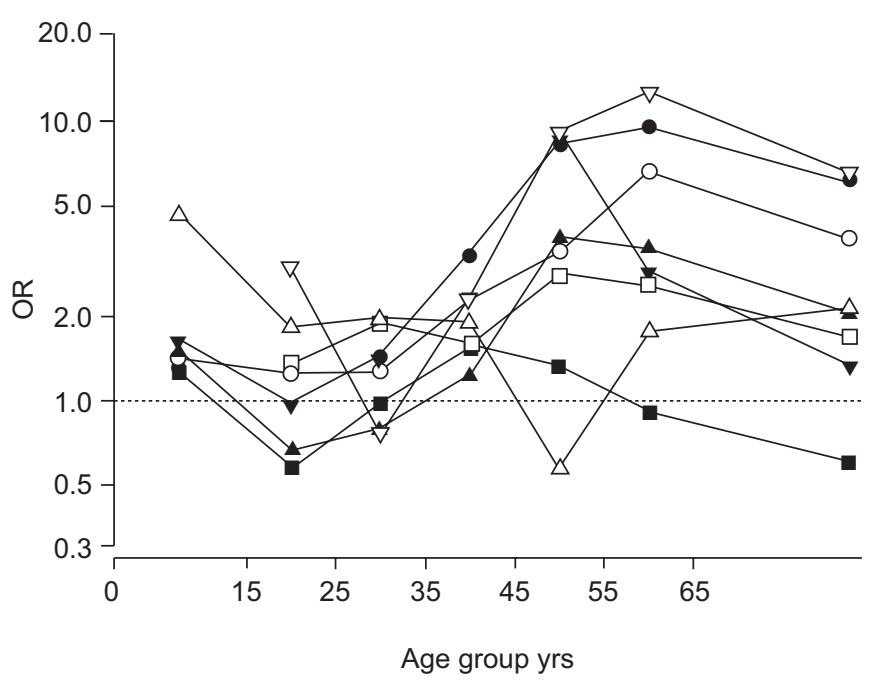

FIGURE 3. Age-specific female-to-male odds ratio (OR) of having extrapulmonary compared with pulmonary tuberculosis by site of extrapulmonary disease ( : Iymphatic, peripheral; ○: lymphatic, intrathoracic; $\mathbf{\square}$ : pleural; $\square$ : genitourinary; $\mathbf{\Delta}$; osteoarticular; $\triangle$ : military; $\mathbf{\nabla}$ : meningeal; $\nabla$ : peritoneal), Germany, 1996-2000 (…....... unity).

purinergic receptor $\mathrm{P}_{2} \mathrm{X}_{7}$ gene increases susceptibility to extrapulmonary tuberculosis in patients from South-east Asia suggests that genetic factors may explain some of these differences [26]. The critical role of vitamin $\mathrm{D}$ in macrophage function is well known and it has long been postulated, particularly in the UK [27], that the high rates of tuberculosis generally seen among immigrants from countries where sunlight is plentiful might, in part, be explained by their relative deficiency of the vitamin upon arrival in countries less favoured by sunshine. Nevertheless, it appears that much of this is conjecture, and other epidemiological reasons can provide a much more parsimonious answer. In particular, the vitamin D hypothesis probably fails to explain organspecific predilections and differences between persons from different areas of origin.

The converse of what was seen among patients from Africa and Asia was seen in patients from countries of the Newly Independent States (former Soviet Union) and former Eastern Europe, who showed a lower risk of extrapulmonary tuberculosis. In this context, it should be noted that, in Estonia for instance, pulmonary tuberculosis increased markedly subsequent to independence, whereas there was little change in the incidence of extrapulmonary tuberculosis, and no increase in those forms considered to have a long latency period [28].

The increased likelihood of extrapulmonary tuberculosis among patients from Africa in particular may be partially explained by the expected higher prevalence of HIV infection amongst this patient group compared with patients from Germany. Since the mid-1980s, HIV infection has been identified as causing more frequent extrapulmonary disease manifestations [29], and this was indeed once an AIDSdefining condition. In the Netherlands, a similar proportion of extrapulmonary tuberculosis among patients from Africa was observed as in the present study, but a much higher proportion was found among persons of Dutch nationality than among those born in Germany in the present study [30]. That the higher prevalence of HIV cannot fully explain the observed differences is evidenced by the example of tuberculosis patients from Asia. This group of patients is expected to show, on average, a lower frequency of HIV infection. However, the preponderance of Asians for lymphatic tuberculosis is well known [31, 32]. Indeed, in a study from New York (NY, USA) on extrapulmonary tuberculosis among immigrants, HIV infection among patients with extrapulmonary tuberculosis was less frequent than among those with pulmonary tuberculosis [33]. This latter study also showed that, among all foreign-born, those from the Newly Independent States (former Soviet Union) had the lowest frequency of extrapulmonary tuberculosis, comparable to those born in the USA.

Smoking appears to increase the risk of pulmonary but not extrapulmonary tuberculosis [34], and would thus increase the odds of extrapulmonary compared with pulmonary tuberculosis in population groups with a lower prevalence of smoking. From the data collected in the present study, it is not possible to evaluate whether or not smoking had an impact on the observed differences.

Immigration is increasing in many European countries and the composition of the immigrant population is changing in pattern. It is thus not unexpected to find the epidemiology of tuberculosis in the immigrant's place of origin increasingly reflected in tuberculosis disease manifestation in their newly adopted residence.

Over a fifth of tuberculosis patients in Germany now present with an extrapulmonary disease manifestation and this proportion is considerably increased among female patients, children and some foreign-born patients, such as Asians and Africans. This calls for considerable diagnostic acumen on the part of physicians treating such patients.

\section{REFERENCES}

1 Rieder HL, Snider DE Jr, Cauthen GM. Extrapulmonary tuberculosis in the United States. Am Rev Respir Dis 1990; 141: 347-351.

2 Farer LS, Lowell AM, Meador MP. Extrapulmonary tuberculosis in the United States. Am J Epidemiol 1979; 109: 205-217.

3 Deutsches Zentralkomitee zur Bekämpfung der Tuberkulose, 27. Informationsbericht. Berlin, Deutsches Zentralkomitee zur Bekämpfung der Tuberkulose, 2002.

4 Brodt HR, Staszewski S, Enzensberger R, et al. Epidemiologie der Tuberkulose bei Patienten mit HIVInfektion der Universitätsklinik Frankfurt. [Epidemiology of tuberculosis in HIV-infected patients of the University Hospital of Frankfurt.] Med Klin (Munich) 1993; 88: 279-286.

5 Müller H. AIDS und Tuberkulose - die Situation in Köln. [AIDS and tuberculosis - the situation in Cologne.] Offentl Gesundheitswes 1991; 53: 23-25.

6 Ferlinz R, Schlegel J. Beeinflusst AIDS die Epidemiologie der Tuberkulose? [Does AIDS influence the epidemiology of tuberculosis?] Pneumologie 1995; 49: 449-454. 
7 Forssbohm M, Loddenkemper R, Rieder HL. Isoniazid resistance among tuberculosis patients by birth cohort in Germany. Int J Tuberc Lung Dis 2003; 7: 973-979.

8 Rieder HL, Watson JM, Raviglione MC, et al. Surveillance of tuberculosis in Europe. Recommendations of a Working Group of the World Health Organization (WHO) and the European Region of the International Union Against Tuberculosis and Lung Disease (IUATLD) for uniform reporting on tuberculosis cases. Eur Respir J 1996; 9: 1097-1104.

9 American Thoracic Society, Centers for Disease Control and Prevention. Diagnostic standards and classification of tuberculosis in adults and children. Am J Respir Crit Care Med 2000; 161: 1376-1395.

10 McCarthy OR. Asian immigrant tuberculosis - the effect of visiting Asia. Br J Dis Chest 1984; 78: 248-253.

11 Rieder HL, Cauthen GM, Kelly GD, Bloch AB, Snider DE Jr. Tuberculosis in the United States. JAMA 1989; 262: 385-389.

12 Lillebaek T, Andersen ÅB, Dirksen A, Smith E, Skovgaard LT, Kok-Jensen A. Persistent high incidence of tuberculosis in immigrants in a low-incidence country. Emerg Infect Dis 2002; 8: 679-684.

13 Rieder HL. Epidemiologic Basis of Tuberculosis Control. Paris, International Union Against Tuberculosis and Lung Disease, 1999.

14 Wallgren A. The time-table of tuberculosis. Tubercle 1948; 29: 245-251.

15 Gordin FM, Slutkin G, Schecter G, Goodman PC, Hopewell PC. Presumptive diagnosis and treatment of pulmonary tuberculosis based on radiographic findings. Am Rev Respir Dis 1989; 139: 1090-1093.

16 Borgdorff MW, Nagelkerke N, van Soolingen D, de Haas PEW, Veen J, van Embden JDA. Analysis of tuberculosis transmission between nationalities in the Netherlands in the period 1993-1995 using DNA fingerprinting. Am J Epidemiol 1998; 147: 187-195.

17 Lillebaek T, Andersen $\AA \mathrm{B}$, Bauer J, et al. Risk of Mycobacterium tuberculosis transmission in a low-incidence country due to immigration from high-incidence areas. J Clin Microbiol 2001; 39: 855-861.

18 Sterling TR, Dorman SE, Chaisson RE, et al. Human immunodeficiency virus-seronegative adults with extrapulmonary tuberculosis have abnormal innate immune responses. Clin Infect Dis 2001; 33: 976-982.

19 Antas PRZ, Ding L, Hackman J, et al. Decreased CD4 ${ }^{+}$ lymphocytes and innate immune responses in adults with previous extrapulmonary tuberculosis. I Allerg Clin Immunol 2006; 117: 916-923.
20 Thompson BC. The pathogenesis of tuberculosis of peripheral lymph nodes. A clinical study of 324 cases. Tubercle 1940; 21: 217-235.

21 Thompson BC. The pathogenesis of tuberculosis of peripheral lymph nodes. A clinical study of 324 cases. Tubercle 1940; 21: 260-268.

22 Enarson DA, Ashley MJ, Grzybowski S, Ostapkowicz E, Dorken E. Non-respiratory tuberculosis in Canada. Am J Epidemiol 1980; 112: 341-351.

23 Lurie MB. Heredity, constitution and tuberculosis. An experimental study. Am Rev Tuberc 1941; 44: Suppl., $1-125$.

24 Ong A, Creasman J, Hopewell PC, et al. A molecular epidemiological assessment of extrapulmonary tuberculosis in San Francisco. Clin Infect Dis 2004; 38: 25-31.

25 Torgersen J, Dorman SE, Baruch N, Hooper N, Cronin W. Molecular epidemiology of pleural and other extrapulmonary tuberculosis: a Maryland state review. Clin Infect Dis 2006; 42: 3175-3182.

26 Fernando SL, Saunders BM, Sluyter R, et al. A polymorphism in the $\mathrm{P}_{2} \mathrm{X}_{7}$ gene increases susceptibility to extrapulmonary tuberculosis. Am J Respir Crit Care Med 2007; 175: 360-366.

27 Davies PDO. Tuberculosis and migration. The Mitchell Lecture 1994. J Roy Coll Phys London 1995; 29: 113-118.

28 Pehme L, Hollo V, Rahu M, Altraja A. Tuberculosis during fundamental societal changes in Estonia with special reference to extrapulmonary manifestations. Chest 2005; 127: 1289-1295.

29 Shafer RW, Kim DS, Weiss JP, Quale JM. Extrapulmonary tuberculosis in patients with human immunodeficiency virus infection. Medicine 1991; 70: 384-397.

30 te Beek LAM, van der Werf MJ, Richter C, Borgdorff MW. Extrapulmonary tuberculosis by nationality, the Netherlands, 1993-2001. Emerg Infect Dis 2006; 12: 1375-1382.

31 Rieder HL. Tuberculosis in an Indochinese refugee camp: epidemiology, management and therapeutic results Tubercle 1985; 66: 179-186.

32 Cowie RL, Sharpe JW. Extra-pulmonary tuberculosis: a high frequency in the absence of HIV infection. Int J Tuberc Lung Dis 1997; 1: 159-162.

33 Wilberschied LA, Kaye K, Fujiwara PI, Frieden TR. Extrapulmonary tuberculosis among foreign-born patients, New York City, 1995 to 1996. J Immigr Health 1999; 1: 65-75.

34 Leung CC, Li T, Lam TH, et al. Smoking and tuberculosis among the elderly in Hong Kong. Am J Respir Crit Care Med 2004; 170: 1027-1033. 